\title{
Does Small Size Vertebral or Vertebrobasilar Artery Matter in Ischemic Stroke?
}

\author{
Jong-Ho Park \\ Department of Neurology, Stroke Center, \\ Myongji Hospital, Kwandong University College of Medicine,
}

South Korea

\section{Introduction}

The vertebral arteries (VAs) are originated from the subclavian arteries and are major arteries for posterior circulation. The left and right VAs are typically described as having 4 segments each $\left(V_{1}\right.$ through $\left.V_{4}\right)$, the first 3 of which are extracranial [1]: the $V_{1}$ segments extend cephalad and posteriorly from the origin of the vertebral arteries between the longus colli and scalenus anterior muscles to the level of the transverse foramina, typically adjacent to the sixth cervical vertebra. The $\mathrm{V}_{2}$ segments extend cephalad from the point at which the arteries enter the most inferior transverse portion of the foramina to their exits from the transverse foramina at the level of the second cervical vertebra. These segments of the left and right VAs therefore have an alternating intraosseous and interosseous course, a unique anatomic environment that exposes the $V_{2}$ segments to the possibility of extrinsic compression from spondylotic exostosis of the spine. Small branches from the $V_{2}$ segments supply the vertebrae and adjacent musculature and, most importantly, may anastomose with the spinal arteries. The $\mathrm{V}_{3}$ segments extend laterally from the points at which the arteries exit the $C_{2}$ transverse foramina, cephalad and posterior to the superior articular process of $C_{2}$, cephalad and medially across the posterior arch of $C_{1}$, and then continue into the foramen magnum. Branches of the $V_{3}$ segments typically anastomose with branches of the occipital artery at the levels of the first and second cervical vertebrae. The $V_{4}$ segments of each vertebral artery extend from the point at which the arteries enter the dura to the termination of these arteries at the vertebrobasilar junction. Important branches of the $V_{4}$ segments include the anterior and posterior spinal arteries, the posterior meningeal artery, small medullary branches, and the posterior inferior cerebellar artery (PICA) [1].

\section{Significance of hypoplastic vertebral artery on ischemic stroke}

Congenital variations in the arrangement and size of the cerebral arteries are frequently recognized [2], ranging from asymmetry or hypoplasia of VA on cerebral angiography. The term, hypoplasia was defined as a lumen diameter of $\leq 2 \mathrm{~mm}$ in a pathoanatomical study [3]. Up to 10 or $15 \%$ of the healthy population have one hypoplastic VA (HVA) and makes little contribution to basilar artery (BA) flow [4,5]. The left VA is dominant in approximately $50 \%$; the right in $25 \%$ and only in the remaining quarter of cases are the two VAs of similar caliber [4]. 
The usual absence of vertebrobasilar insufficiency symptoms among people with HVA has led to an underestimation of clinical significance of HVA. However, ipsilateral HVA is commonly noted in patients with PICA infarction (Fig. 1-A and 1-B) or lateral medullary infarction (LMI, Fig. 2-A and 2-B), suggesting that HVA confers an increased probability of ischemic stroke [6].
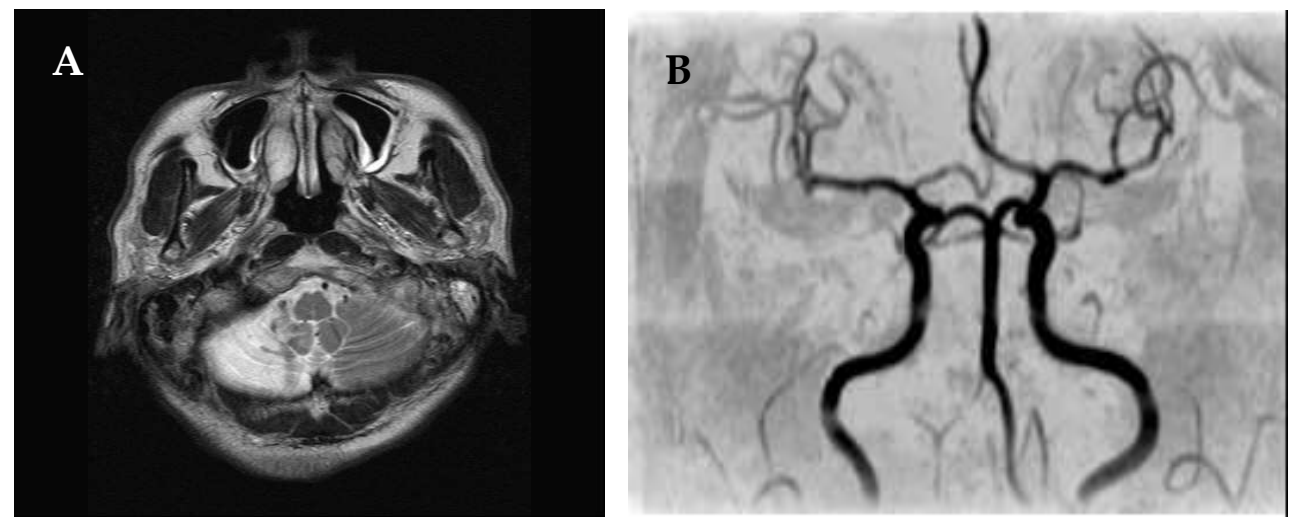

PICAI, posterior inferior cerebellar artery infarction; VA, vertebral artery

Fig. 1. A case of right PICAI with the responsible VA showing hypoplasia.
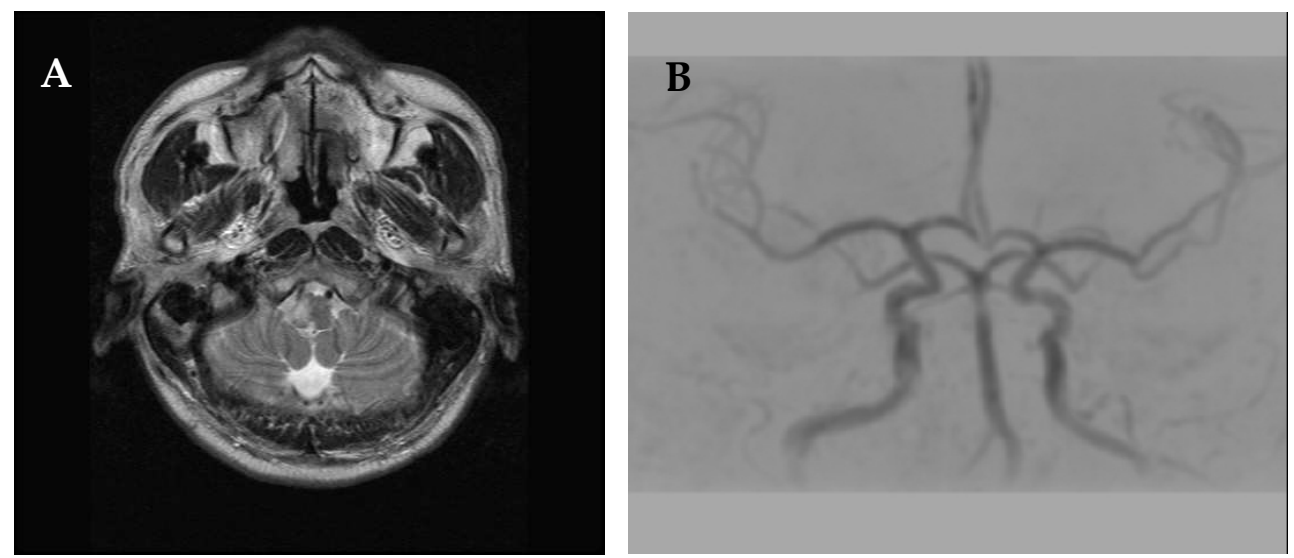

LMI, lateral medullary infarction; VA, vertebral artery

Fig. 2. A case of LMI with the responsible VA showing hypoplasia

Although the HVA is observed in up to 10 or $15 \%$ of normal populations [4, 5], there may be many patients with HVA who suffered from posterior circulation stroke (PCS). A Taiwan study [7] examined 191 acute ischemic stroke patients (age $55.8 \pm 14.0$ years) using a cervical magnetic resonance angiogram (MRA) and a duplex ultrasonography on bilateral VA $\left(\mathrm{V}_{2}\right.$ segment level) with flow velocities and vessel diameter within $72 \mathrm{~h}$ after stroke onset. The overall incidence of a unilateral congenital HVA was higher especially in cases of brainstem/cerebellar infarction $(P=0.022)$. Subjects with HVA had a preponderance of the large-artery atherosclerosis subtype and a topographic preponderance of ipsilateral PCS. 
They suggested HVA seemed a contributing factor of acute ischemic stroke, especially in PCS territories. Perren et al [8] investigated 725 first-ever stroke patients, using color-coded duplex flow imaging of the $V_{2}$ segment, and showed that HVA (diameter $\leq 2.5 \mathrm{~mm}$ ) was more frequent in PCS (mostly brainstem and cerebellum) than in strokes in other territories $(13 \%$ vs. $4.6 \%, P<0.001)$, whereas distribution of all other risk factors (e.g. hypertension, hyperlipidemia, diabetes, smoking) were comparable $(P>0.05)$. They concluded that HVA may be predisposed to PCS.

Park et al [6] investigated the frequency and clinical relevance of HVA in 529 stroke patients [303 anterior (ACS) and 226 PCS] and in 306 normal healthy people. When classified by stroke location, patients with PCS $(45.6 \%)$ showed more significant frequency of HVA than those with ACS $(27.1 \%)$ and normal healthy people (26.5\%, $P<0.001$ for all). Out of 226 patients with PCS, ischemic lesion distribution of VA territory stroke (PICA or LMI) in 102 PCS patients was examined by the group of VA (hypoplastic, dominant, and symmetric). HVA was defined as a VA with a diameter of $\leq 2 \mathrm{~mm}$, and the larger (contralateral) one was defined as a dominant VA. The VA symmetry was defined when both VAs have a diameter $>2 \mathrm{~mm}$. Cardioembolic stroke was more prevalent in the symmetric group $(P<0.05)$. In terms of demographic features, risk factors, and laboratory findings, there were no significant differences. Acute ischemic lesions of the VA territory stroke were present mostly in the PICA territory and then lateral medulla, PICA territory + lateral medulla, PICA territory + BA territory or more. It is because the HVA may terminate in the PICA or extends beyond the PICA to the BA, contributing little to BA blood flow [1].

Ischemic lesion distributions in the VA feature groups are displayed in Fig. 3 [6]. LMI and PICAI were dominant in the HVA group. Multiple infarctions, such as LMI + PICAI, and PICAI $+\geq$ BA territory infarction were also more prominent in the HVA group than in the symmetric group. In the dominant VA group, the lesions were present dominantly in the PICA territory, and then in the lateral medulla. Ipsilateral HVA tended to predict the involvement of multiple and extensive lesions, and a higher incidence of steno-occlusion.

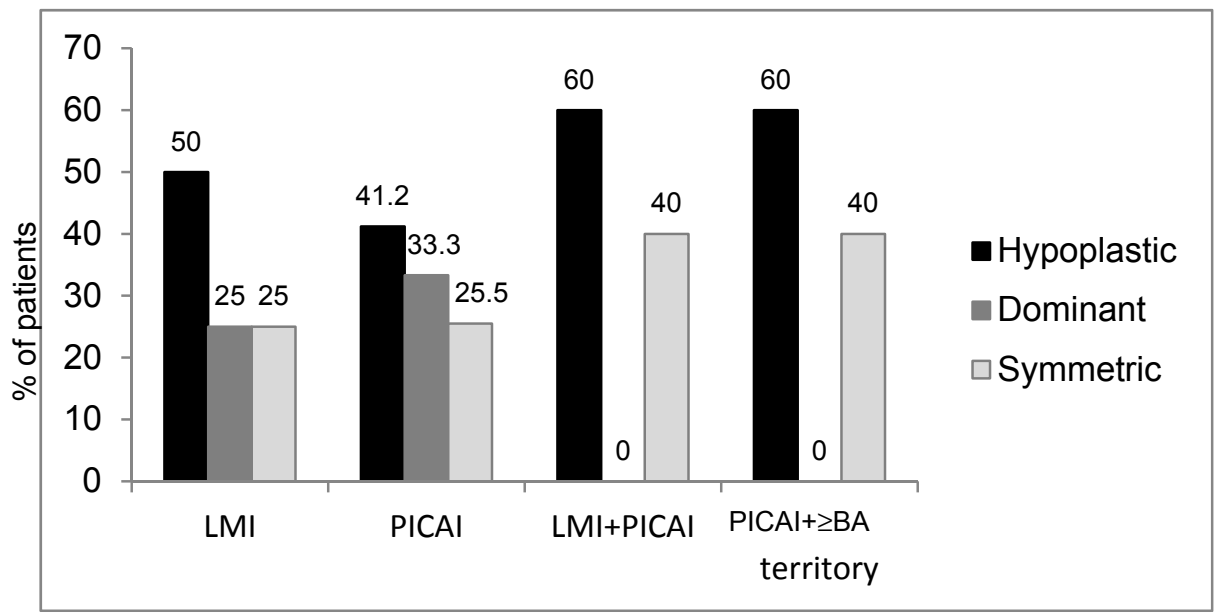

LMI, lateral medullary infarction; PICAI, posterior inferior cerebellar artery infarction; $\geq \mathrm{BA}$, more than basilar artery.

Fig. 3. Lesion distribution by VA group in patients with VA territory infarction [6] 
Stenosis or occlusion of the intracranial VA was significantly more prevalent in the hypoplastic group (vs. dominant or symmetric group). Taking these into account, HVA may be etiopathogenetically implicated in PCS, especially the VA territory.

In VA territory stroke, cardioembolism and artery-to-artery embolism are the two most common stroke mechanisms [9]. Most of VA territory stroke patients with ipsilateral HVA showed stenosis/occlusion and multiple ischemic lesions were dominant in the HVA group. Cardioembolic stroke was least prevalent in the HVA group. It is thought that luminal narrowing of the HVA might make it less feasible for cardiogenic emboli to pass through it. Accordingly, HVA-related ischemic stroke is based on large-artery atherosclerosis [6]. The HVA may not be an uncommon asymptomatic if there are no risk factors, but it may contribute to PCS in some patients, if additional risk factors are present [10].

\section{Ischemic stroke patterns and hemodynamic features in patients with HVA or small vertebrobasilar artery}

In terms of BA hypoplasia $(\mathrm{BAH})$, there have been few case reports regarding an association between BAH and PCS [11, 12]. A recent study showed that BAH, defined as a diameter <2 mm was 3-fold higher in patients with PCS (vs. ACS), in which the stroke subtype was undetermined or lacunar stroke [13]. Localization of PCS was predominant in pons or cerebellar territories $(71.4 \%)$. Half of PCS of BAH patients were characteristic of small infarcts by pontic-penetrating arteries [13]. The blood flow volume and velocity might be decreased in small-sized (hypoplastic artery), resulting in a higher susceptibility to prothrombotic or atherosclerosis processes than normal-sized artery [14].

Actually however, BAH usually accompanied by HVA which can be seen on MRA or transfemoral cerebral angiography (TFCA). Age-related atherosclerosis might gradually restrict the compliance of the vertebro-basilar artery hypoplasia. Sudden exertion or emotional stress would incur a paradoxical cerebral vasoconstriction and the following transient hemodynamic insufficiency may occur [15].

How do ischemic patterns in patients with hypoplastic VBA differ from those in subjects with a normal-sized VBA? Recently ischemic patterns, collateral features, and stroke mechanisms in 37 acute $(2.3 \pm 1.1$ days after stroke onset) PCS patients after stroke onset with small vertebrobasilar artery (SVBA) were investigated [16]. The mean diameter of the normal BA has been reported to be $3.17 \mathrm{~mm}$ [17] and the HVA was defined to have a lumen diameter of less than 2-3 mm [18, 19]. Accordingly, SVBA was defined as a lumen diameter of $<3 \mathrm{~mm}$. The diameter of SVBA was measured in the mid-portion level of the BA and the $\mathrm{V}_{2}$ of the largest VA by using magnified images of MRA. Thirty acute (2.2 \pm 1.4 days after stroke onset) PCS patients with normal-sized BA ( $>3 \mathrm{~mm}$ in diameter) were compared as the control group.

Ischemic lesions were predominantly observed in the cerebellum and/or medulla (VA territory) [16]. All subjects had fetal posterior circulation (FPC) from the internal carotid artery to the posterior cerebral artery. Many of the patients had distal or diffuse VA stenosis/occlusion $(88.9 \%)$ and long circumferential artery $(77.8 \%)$. As the degree of VA disease increased (i.e., from "none" to "unilateral" to "bilateral"), the frequency of long circumferential artery (posterior/inferior/anterior cerebellar artery) prominence (i.e., "none," "one," and "two or more") tended to increase $(P<0.05)$. Ischemic lesions were predominantly observed in the cerebellum and/or medulla in the VA territory $(72.2 \%)$. Relatively small, scattered infarcts were observed in patients with SVBA than in those with 
stenotic normal-sized VBA (Fig. 4-A and 4-B). In atherothrombotic patients, infratentorial PCS might occur following artery-to-artery embolism from the low-flowed or stenotic VA to long circumferential artery. Regardless of extensive arterial lesions, relatively small infarcts may be due to previously established collaterals from the long circumferential artery (e.g. PICA, anterior inferior cerebellar artery, superior cerebellar artery), which could compensate for the defects in the infratentorial area.
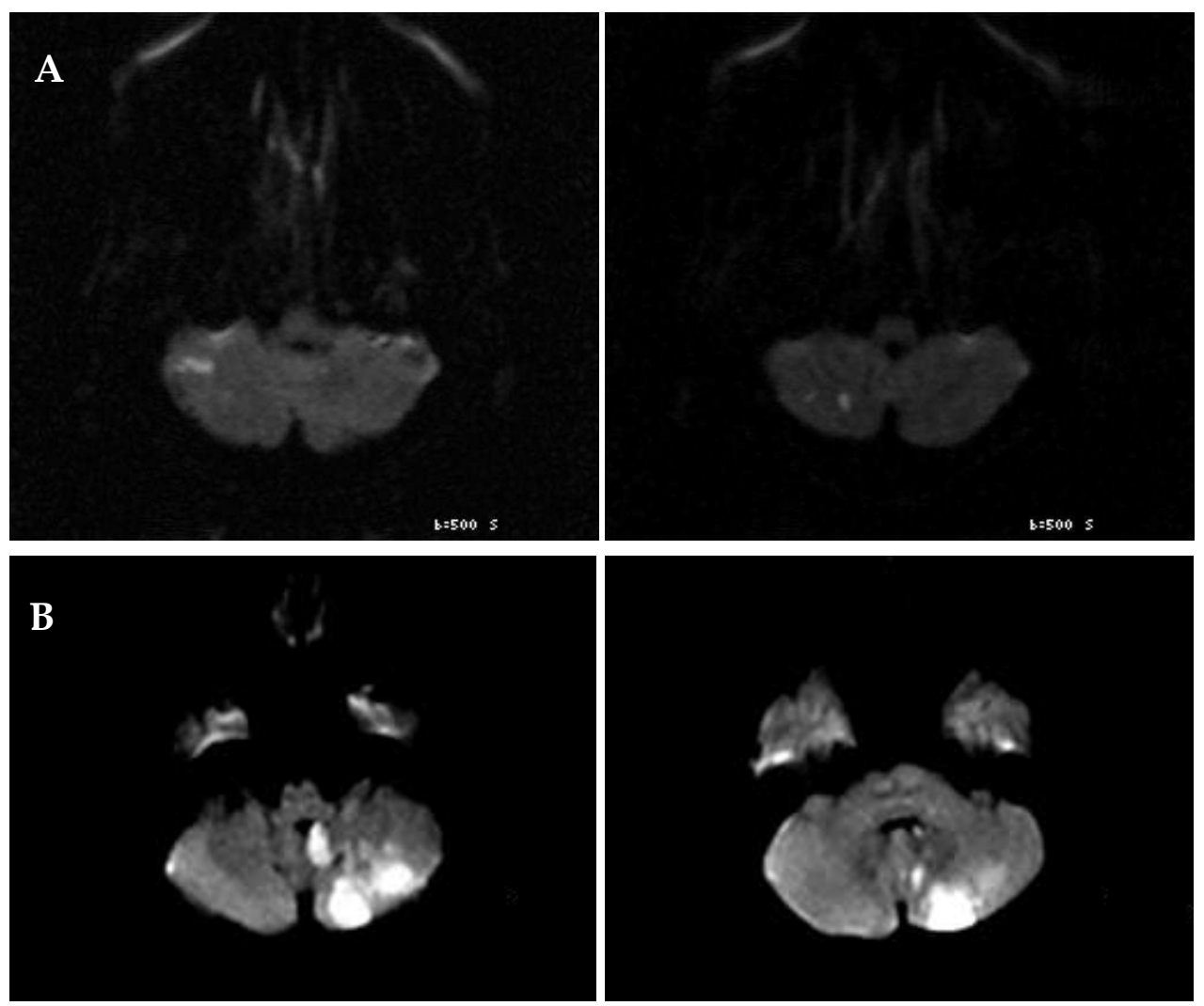

SVBA, small vertebrobasilar artery

Fig. 4. Relatively small, scattered infarcts were observed in patients with SVBAs (Fig. 4-A) than in those with stenotic normal-sized VBA (Fig. 4-B).

The stenotic normal-sized VBA group showed relatively large, conglomerate infarct patterns compared with those of stenotic SVBA group. However, the ischemic findings of some patients with normal-sized VBA were similar to those of SVBA group. They had common feature that showed extracranial focal VA lesion (below the $V_{3}$ ).

\section{Association of fetal posterior circulation with PCS}

Fetal posterior circulation (FPC) is a fetal variant of the posterior cerebral artery from the internal carotid artery. The prevalence of FPC is reported to be $32 \%$ in the general 
population [20]. A recent study showed the existent varieties of FPC (bilateral in $88.9 \%$ of patients), and suggested that FPC may compensate the posterior circulation zone for the hemodynamic insufficiency caused by SVBA [16]. Since the cerebellar tentorium impedes the formation of a leptomeningeal connection, FPC does not contribute to the perfusion of the infratentorial area [21]. Consequently, FPC makes the development of leptomeningeal collaterals between the internal carotid artery and the vertebrobasilar system impossible [21]. The result [16] that most of the infratentorial lesions originated from the cerebellum and/or medulla (VA territory) or the pons (BA territory) are consistent with that [21] FPC would not be able to protect the infratentorial area against PCS.

\section{SVBA is of congenital origin or a consequence of multiple or longitudinal atherosclerotic narrowing?}

Embryologically, if the BA does not become the main source of blood supply to the developing posterior cerebral arteries, the FPC might persist and remain large in size [22]. The observations that all the study patients had FPC and that the FPC was larger than the vertebrobasilar artery may support the hypothesis that the SVBA is congenitally small rather than acquired [16].

\section{Hemodynamic mechanism of hypoplastic artery causing to ischemic stroke}

Why does size matter and how the smaller artery are susceptible to occlusion? Size alone cannot be explained because many intracranial arteries are smaller than the hypoplastic arteries and they are not predisposed to occlude [14]. An interaction between blood pressure, blood constituents and the rheology and physics of blood flow at various arterial locations might affect arterial occlusion [14]. The HVA, which shows lower mean flow volume [7, 23, 24] and decreased flow velocities [24], seems to be more susceptible to prothrombotic or atherosclerotic processes than normal or dominant VAs. Under the decreased VA flow capacity, hypoplastic artery is prone to collapse as a result of Bernoulli's effect [25]. Therefore, it is postulated that a HVA can result in the ipsilateral occlusion of this vessel due to a direct decrease in blood flow and easy collapse of the vessel caused by the smaller VA caliber [26]. The HVA may further contribute to PCS, if additional risk factors such as hypertension, diabetes exist. Most of patients with VA territory stroke who showed VA stenosis/occlusion had HVA [6].

\section{Characteristic findings of HVA or SVBA by ultrasonography}

Jeng et al attempted to attain reference values for VA flow volume by color Doppler ultrasonography, analyze age and gender effects on VA flow volume and develop a definition of HVA [5]. Color Doppler ultrasonography was performed in 447 subjects free of stroke or carotid stenosis. They found significant asymmetries in diameter, flow velocities and flow volume with left-sided dominance. Diameters were different on left $(0.297 \pm 0.052 \mathrm{~cm})$ and right $(0.323 \pm 0.057 \mathrm{~cm})$ sides $(P<0.001)$. Flow volume was different on right $(83.0 \pm 36.9 \mathrm{~mL} / \mathrm{min})$ and left $(96.6 \pm 42.4)$ sides $(P<0.001)$. Women had significantly smaller diameters, higher flow velocities and lower resistance indexes (RIs) than men. VA flow volume did not change with aging. They defined HVA as a significant decrease in flow velocities and increase in RI for VA diameters $<0.22 \mathrm{~cm}$. This definition is 
supported by findings of an increase in ipsilateral flow resistance ( $R I \geq 0.75)$, contralateral diameter (side-to-side diameter difference $\geq 0.12 \mathrm{~cm}$ ), and flow volume (side-to-side flow volume ratio $\geq 5$ ).

The stroke mechanism of PCS patients with SVBA was mostly large-artery atherosclerosis and they showed stenosis or poor perfusion state (from blunted to absent signal) of VA and/or BA on transcranial Doppler [16]. According to the Bernoulli's principle, the greater the flow velocity, the less the lateral pressure on the vessel wall. Therefore, if an hypoplastic artery is narrowed by atherosclerotic plaque, the flow velocity would increase through the constriction and decrease in lateral pressure.

\section{Evaluation of patients with HVA or SVBA}

Evaluation of the patient with presumed vertebrobasilar insufficiency or PCS should begin with a thorough clinical history and examination followed by noninvasive imaging (e.g. MRA) as for patients with carotid artery disease [27]. In case of a patient with symptomatic HVA or SVBA, which was initially seen on three-dimension time-of-flight (3D TOF) circle of Willis MRA, contrast-enhanced neck computed tomography angiography (CTA) or contrast-enhanced neck MRA is recommended.

Contrast-enhanced CTA and MRA were associated with higher sensitivity (94\%) and specificity (95\%) than duplex ultrasonography (sensitivity 70\%), and CTA had slightly superior accuracy [28]. Because neither CTA nor MRA reliably delineates the origins of theVAs, catheter-based contrast angiography is typically required before revascularization for patients with symptomatic posterior cerebral ischemia [28].

In patient with SVBA, 3D TOF MRA can barely demonstrate VBA configuration. Even the VBA system cannot be seen entirely according to the degree of atherosclerotic burden. TFCA enables us to see collaterals from the VBA. In some patients, TFCA provides hemodynamical information that upper brainstem was supplied from retrograde filling of BA through the fetal circulation. Rarely, there can be seen some collaterals around the VBA in a patient whose VBA is nearly invisible in 3D TOF MRA. Such findings are correlated with collaterals from long circumferential arteries in TFCA. In fact, advanced arterial narrowing from the VA orifice made it difficult to access the entire VBA by TFCA. The TFCA may be actually dangerous than contrast-enhanced imaging because of catheterinduced embolization in an atherogenic small caliber.

\section{Management of PCS patients with HVA or SVBA}

PCS patients by stenotic HVA or SVBA is encountered very less commonly in clinical practice than those with usual PCS, and the evidence-based guideline for evaluation and management is less substantial.

\subsection{Medical therapy}

Therapeutic guidelines are as same as patients with VA disease [1]: antiplatelet drug therapy is recommended as part of the initial management for patients with symptomatic HVA or SVBA. Aspirin (81 to $325 \mathrm{mg}$ daily), the combination of aspirin plus extendedrelease dipyridamole ( 25 and $200 \mathrm{mg}$ twice daily, respectively), and clopidogrel (75 $\mathrm{mg}$ daily) are acceptable options. Selection of an antiplatelet regimen should be individualized 
on the basis of patient risk factor profiles, cost, tolerance, and other clinical characteristics, as well as guidance from regulatory agencies [31-36].

There is no consensus about anticoagulation therapy. Most of the HVA- or SVBA-related ischemic stroke is based on large-artery atherosclerosis $[6,16]$. The WASID (Warfarin versus Aspirin for Symptomatic Intracranial Disease) trial found aspirin and warfarin to be equally efficacious after initial noncardioembolic ischemic stroke [37, 38]. Accordingly, anticoagulation may not be generally recommended as a rational therapeutic option in PCS patients with HVA or SVBA.

\subsection{Endovascular revascularization}

In terms of endovascular interventions, although angioplasty and stenting of the VAs are technically feasible, as for high-risk patients with carotid artery stenosis, there is insufficient evidence from randomized trials to demonstrate that endovascular management is superior to best medical management [1].

\subsection{Surgical revascularization}

When both VAs are patent and one symptomatic VA has a definite stenotic lesion with the uninvolved larger VA supplying sufficient blood flow to the BA, corrective surgery may be effective [1]. The surgical approach to atherosclerotic lesions at the origin of the VA includes trans-subclavian vertebral endarterectomy, transposition of the VA to the ipsilateral common carotid artery, and reimplantation of the VA with vein graft extension to the subclavian artery. Distal reconstruction of the VA, necessitated by total occlusion of the midportion, may be accomplished by anastomosis of the principal trunk of the external carotid artery to the VA at the level of the second cervical vertebra [39].

\section{Summary}

The PCS group showed a higher frequency of HVA than the ACS group and all the patients with unilateral HVA among those with VA territory stroke showed ipsilateral ischemic lesions. These findings provide evidence that HVA may be etiopathogenetically implicated in PCS [6]. Patients with SVBA showed FPC with bilateral dominance and FPC may compensate the supratentorial posterior circulation zone (e.g. temporooccipital area) for the hemodynamic insufficiency: most of the infratentorial lesions originated from the cerebellum and/or medulla (VA territory) or the pons (BA territory). Regardless of the presence of extensive arterial lesions (atherothrombotic SVBA), relatively small infarcts can be attributed to the established leptomeningeal collaterals from the long circumferential arteries that can compensate for the defects in the infratentorial area. Thus, the degree of collateral development along with a chronic process of atherothrombosis may determine the pattern (particularly, the size) of an ischemic lesion [16].

Optimum management of PCS patients with HVA or SVBA is not as well established as that for patients with carotid stenosis [1]. Considering for small-diameter vascular state, medical therapy and lifestyle modification to reduce atherosclerotic burden would be most appropriate, which is identical with patients with VA disease [29, 30]. This would be optimal measures in principle directed at reduction of atherosclerotic burden and the prevention of recurrent PCS, although none have been evaluated in randomized trials about medical versus surgical approaches. 


\section{References}

[1] Brott TG, Halperin JL, Abbara S, Bacharach JM, Barr JD, Bush RL, Cates CU, Creager MA, Fowler SB, Friday G, Hertzberg VS, McIff EB, Moore WS, Panagos PD, Riles TS, Rosenwasser RH, Taylor AJ. 2011 ASA/ACCF/AHA/AANN/AANS/ACR/ASNR/CNS/SAIP/SCAI/SIR/SNIS /SVM/SVS Guideline on the Management of Patients With Extracranial Carotid and Vertebral Artery Disease. A Report of the American College of Cardiology Foundation/American Heart Association Task Force on Practice Guidelines, and the American Stroke Association, American Association of Neuroscience Nurses, American Association of Neurological Surgeons, American College of Radiology, American Society of Neuroradiology, Congress of Neurological Surgeons, Society of Atherosclerosis Imaging and Prevention, Society for Cardiovascular Angiography and Interventions, Society of Interventional Radiology, Society of NeuroInterventional Surgery, Society for Vascular Medicine, and Society for Vascular Surgery. Stroke 2011 [Epub ahead of print]

[2] Caldemeyer K, Carrico J, Mathews V. The radiology and embryology of anomalous arteries of the head and neck. AJR Am J Roentgenol 1998;170:197-203.

[3] Fisher CM, Gore I, Okabe N, et al. Atherosclerosis of the carotid and vertebral arteriesextracranial and intracranial. J Neuropathol Exp Neurol 1965;24:455-476.

[4] Cloud GC, Markus HS. Diagnosis and management of vertebral artery stenosis. Q J Med 2003;96:27-34.

[5] Jeng JS, Yip PK. Evaluation of vertebral artery hypoplasia and asymmetry by color-coded duplex ultrasonography. Ultrasound in Med Biol 2004;30:605-609.

[6] Park JH, Kim JM, Roh JK. Hypoplastic vertebral artery; frequency and associations with ischemic stroke territory. J Neurol Neurosurg Psychiatry 2007;78:954-958.

[7] Chuang YM, Huang YC, Hu HH, Yang CY. Toward a further elucidation: role of vertebral artery hypoplasia in acute ischemic stroke. Eur Neurol 2006;55:193197.

[8] Perren F, Poglia D, Landis T, Sztajzel R. Vertebral artery hypoplasia: a predisposing factor for posterior circulation stroke? Neurology 2007;68:65-67.

[9] Caplan LR, Wityk RJ, Glass TA, Tapia J, Pazdera L, Chang HM, Teal P, Dashe JF, Chaves CJ, Breen JC, Vemmos K, Amarenco P, Tettenborn B, Leary M, Estol C, Dewitt LD, Pessin MS. New England Medical Center Posterior Circulation registry. Ann Neurol 2004;56:389-398.

[10] Giannopoulos S, Markoula S, Kosmidou M, Pelidou SH, Kyritsis AP. Lateral medullary ischaemic events in young adults with hypoplastic vertebral artery. J Neurol Neurosurg Psychiatry 2007;78:987-989.

[11] Szdzuy D, Lehmann R. Hypoplastic distal part of the basilar artery. Neuroradiology. 1972;4:118-120.

[12] Hegedus K. Hypoplasia of the basilar artery. Three case reports. Eur Arch Psychiatr Neurol Sci 1985;234:395-398. 
[13] Olindo S, Khaddam S, Bocquet J, Chausson N, Aveillan M, Cabre P, Smadja D. Association between basilar artery hypoplasia and undetermined or lacunar posterior circulation ischemic stroke. Stroke 2010;41:2371-2374.

[14] Caplan LR. Arterial occlusions: does size matter? J Neurol Neurosurg Psychiatry 2007;78: 916.

[15] Chuang YM, Hu HH, Pan PJ. Cerebral syncope: insights from Valsalva maneuver. Eur Neurol 2005;54:98-102.

[16] Park JH, Roh JK, Kwon HM. Ischemic patterns and hemodynamic features of hypoplastic vertebrobasilar artery. J Neurol Sci 2009;287:227-235.

[17] Smoker WR, Price MJ, Keyes WD, Corbett JJ, Gentry LR. High-resolution computed tomography of the basilar artery: Normal size and position. AJNR Am J Neuroradiol 1986;7:55-60.

[18] Fisher CM, Gore I, Okabe N, White PD. Atherosclerosis of the carotid and vertebral arteries-Extracranial and intracranial. J Neuropathol Exp Neurol 1965;24:455-476.

[19] Touboul PJ, Bousser MG, LaPlane D, Castaigne P. Duplex scanning of normal vertebral arteries. Stroke 1986;17:921-923.

[20] Krabbe Hartkamp MJ, Van der Grond J, de Leeuw FE, de Groot JC, Algra A, Hillen B, Breteler MM, Mali WP. Circle of Willis: morphologic variation on three-dimensional time-of-flight MR angiograms. Radiology 1998;207:103111.

[21] van Raamt AF, Mali WP, van Laar PJ, van der Graaf Y. The fetal variant of the circle of Willis and its influence on the cerebral collateral circulation. Cerebrovasc Dis 2006;22:217-224.

[22] Chaturvedi S, Lukovits TG, Chen W, Gorelick PB. Ischemia in the territory of a hypoplastic vertebrobasilar system. Neurology 1999;52:980-983.

[23] Schöning M, Hartig B. The development of hemodynamics in the extracranial carotid and vertebral arteries. Ultrasound Med Biol 1998;24:655-662.

[24] Bartels E, ed. Vertebral sonography. Color-coded duplex ultrasonography of the cerebral vessels:atlas and manual. Stuttgart: Schattauer, 1999:113-155.

[25] Binns RL, Ku DN. Effect of stenosis on wall motion. A possible mechanism of stroke and transient ischemic attack. Arteriosclerosis 1989;9:842-847.

[26] Hong JM, Chung JS, Bang OY, Yong SW, Joo IS, Huh K. Vertebral artery dominance contributes to basilar artery curvature and peri-vertebrobasilar junctional infarcts. $J$ Neurol Neurosurg Psychiatry 2009;80:1087-1092.

[27] Blacker DJ, Flemming KD, Wijdicks EF. Risk of ischemic stroke in patients with symptomatic vertebrobasilar stenosis undergoing surgical procedures. Stroke 2003;34:2659-2663.

[28] Long A, Lepoutre A, Corbillon E, Branchereau A. Critical review of non- or minimally invasive methods (duplex ultrasonography, MR- and CT-angiography) for evaluating stenosis of the proximal internal carotid artery. Eur J Vasc Endovasc Surg 2002;24:43-52. 
[29] Third Report of the National Cholesterol Education Program (NCEP) Expert Panel on Detection, Evaluation, and Treatment of High Blood Cholesterol in Adults (Adult Treatment Panel III) final report. Circulation 2002;106:31433421.

[30] Ginsberg HN, Kris-Etherton P, Dennis B, Elmer PJ, Ershow A, Lefevre M, Pearson T, Roheim P, Ramakrishnan R, Reed R, Stewart K, Stewart P, Phillips K, Anderson N. Effects of reducing dietary saturated fatty acids on plasma lipids and lipoproteins in healthy subjects: the DELTA Study, protocol 1. Arterioscler Thromb Vasc Biol 1998;18:441-449.

[31] Adams RJ, Albers G, Alberts MJ, Benavente O, Furie K, Goldstein LB, Gorelick P, Halperin J, Harbaugh R, Johnston SC, Katzan I, Kelly-Hayes M, Kenton EJ, Marks M, Sacco RL, Schwamm LH; American Heart Association; American Stroke Association. Update to the AHA/ASA recommendations for the prevention of stroke in patients with stroke and transient ischemic attack. Stroke 2008;39:16471652.

[32] Antithrombotic Trialists' Collaboration. Collaborative meta-analysis of randomised trials of antiplatelet therapy for prevention of death, myocardial infarction, and stroke in high risk patients. BMJ 2002;324:71-86

[33] CAPRIE Steering Committee. A randomised, blinded, trial of clopidogrel versus aspirin in patients at risk of ischaemic events (CAPRIE). Lancet 1996;348:1329_ 1339.

[34] Diener HC, Bogousslavsky J, Brass LM, Cimminiello C, Csiba L, Kaste M, Leys D, Matias-Guiu J, Rupprecht HJ; MATCH investigators. Aspirin and clopidogrel compared with clopidogrel alone after recent ischaemic stroke or transient ischaemic attack in high-risk patients (MATCH): randomised, double-blind, placebo-controlled trial. Lancet 2004;364:331-337.

[35] Diener HC, Cunha L, Forbes C, Sivenius J, Smets P, Lowenthal A. European Stroke Prevention Study 2. Dipyridamole and acetylsalicylic acid in the secondary prevention of stroke. J Neurol Sci 1996;143:1-13.

[36] Sacco RL, Diener HC, Yusuf S, Cotton D, Ounpuu S, Lawton WA, Palesch Y, Martin RH, Albers GW, Bath P, Bornstein N, Chan BP, Chen ST, Cunha L, Dahlöf B, De Keyser J, Donnan GA, Estol C, Gorelick P, Gu V, Hermansson K, Hilbrich L, Kaste M, Lu C, Machnig T, Pais P, Roberts R, Skvortsova V, Teal P, Toni D, Vandermaelen C, Voigt T, Weber M, Yoon BW; PRoFESS Study Group. Aspirin and extended-release dipyridamole versus clopidogrel for recurrent stroke. N Engl J Med 2008;359:12381251.

[37] Kasner SE, Lynn MJ, Chimowitz MI, Frankel MR, Howlett-Smith H, Hertzberg VS, Chaturvedi S, Levine SR, Stern BJ, Benesch CG, Jovin TG, Sila CA, Romano JG; Warfarin Aspirin Symptomatic Intracranial Disease (WASID) Trial Investigators. Warfarin vs aspirin for symptomatic intracranial stenosis: subgroup analyses from WASID. Neurology 2006;67:1275-1278.

[38] Benesch CG, Chimowitz MI. Best treatment for intracranial arterial stenosis? 50 years of uncertainty. The WASID Investigators. Neurology 2000;55:465-466. 
[39] Berguer R, Bauer RB. Vertebral artery reconstruction: a successful technique in selected patients. Ann Surg 1981;193:441-447. 


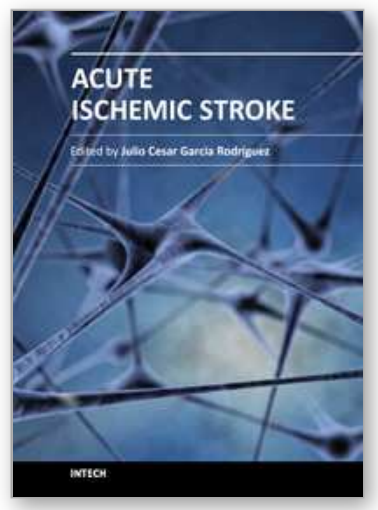

\author{
Acute Ischemic Stroke \\ Edited by Prof. Julio Cesar Garcia Rodriguez
}

ISBN 978-953-307-983-7

Hard cover, 236 pages

Publisher InTech

Published online 18, January, 2012

Published in print edition January, 2012

Despite significant technological advances in recent years, their impact on our overall health and social, wellbeing is not always clear to see. Perhaps, one of the best examples of this can be highlighted by the fact that mortality rates as a result of cerebrovascular diseases have hardly changed, if at all. This places cerebrovascular diseases as one of the most prominent causes of both disability and death. In Cuba, for instance, a total of 22,000 cases of cerebrovascular diseases are reported each year in a country where life expectancy should increase to 80 years in the near future. In such a situation, to have a book that includes in a clear and summarized way, a group of topics directly related to the preclinical investigations advances and the therapeutic procedures for the cerebrovascular disease in its acute phase constitutes a useful tool for the wide range of the contributors to this affection's problems solution. In this group is included students, professors, researchers, and health policy makers whose work represents one of the greatest social and human impact challenges of the XXI century basic and clinical neurosciences.

\title{
How to reference
}

In order to correctly reference this scholarly work, feel free to copy and paste the following:

Jong-Ho Park (2012). Does Small Size Vertebral or Vertebrobasilar Artery Matter in Ischemic Stroke?, Acute Ischemic Stroke, Prof. Julio Cesar Garcia Rodriguez (Ed.), ISBN: 978-953-307-983-7, InTech, Available from: http://www.intechopen.com/books/acute-ischemic-stroke/does-small-size-vertebral-or-vertebrobasilar-arterymatter-in-ischemic-stroke-

\section{INTECH}

open science | open minds

\section{InTech Europe}

University Campus STeP Ri

Slavka Krautzeka 83/A

51000 Rijeka, Croatia

Phone: +385 (51) 770447

Fax: +385 (51) 686166

www.intechopen.com

\section{InTech China}

Unit 405, Office Block, Hotel Equatorial Shanghai

No.65, Yan An Road (West), Shanghai, 200040, China

中国上海市延安西路65号上海国际贵都大饭店办公楼405单元

Phone: +86-21-62489820

Fax: $+86-21-62489821$ 
(C) 2012 The Author(s). Licensee IntechOpen. This is an open access article distributed under the terms of the Creative Commons Attribution 3.0 License, which permits unrestricted use, distribution, and reproduction in any medium, provided the original work is properly cited. 